\title{
Heroin addiction in British prisons: an interpretative phenomenological analysis
}

\begin{abstract}
Personal experiences of heroin addiction in prison have been often overlooked in research. This study aims to examine the lived experience of former prisoners who experienced heroin addiction during incarceration, with a specific focus on the social and psychological components of the phenomenon. Semi-structured interviews were carried out with four participants who had been diagnosed with opioid dependence. Transcripts of the interviews were analysed using Interpretative Phenomenological Analysis (IPA). Four superordinate themes emerged from the analysis. These were: heroin as emotion regulator, relationship with heroin, feelings of isolation and fear, and conceptualisation of heroin on behaviour change. Superordinate themes with the corresponding subthemes are presented. This study brings attention to individuals relationship with heroin and impact of heroin use on interpersonal relationships. Further studies and practical application of scientific knowledge are required to effectively support prisoners with heroin addiction and help them achieve recovery.
\end{abstract}

Keywords: heroin addiction, heroin dependence, prison, prisoners, incarceration, IPA
Volume 5 Issue 2 - 2018

\author{
Lana Durjava,Amanda Visick, Samantha \\ Banbury \\ School of Psychology, London Metropolitan University, UK
}

Correspondence: Amanda Visick, School of Psychology, London Metropolitan University, 166-220 Holloway Road, London, N78DB, UK, Email A.Visick@londonmet.ac.uk

Received: March 22, 2018 | Published: April 05, 2018

\section{Background}

Whilst the use of new psychoactive substances in prison has increased, heroin use is nevertheless still a concern. ${ }^{1}$ Compared to other drugs, the use of heroin in prison tends to be precipitated and perpetuated for longer periods compared to the use of cocaine and amphetamine. ${ }^{2,3}$ Further, prisoners often present with dual diagnosis and polysubstance addiction compounding the biopsychosocial problems associated with substance use. ${ }^{4}$ This raises concerns for the well-being of prisoners, staff and to prison security. ${ }^{1}$

Heroin addiction is a disorder with symptomatology of drug cravings, increased tolerance, physical dependence and withdrawal symptoms, compulsive drug use, preoccupation with drug use and continuation of drug use despite negative consequences. ${ }^{5}$ Heroin use carries multiple health, legal and social implications such as increased risk of blood borne viruses, infections, injecting related complications, poor health, criminal activity, unemployment and impaired parenting. ${ }^{6-8}$ Heroin use in a prison setting carries additional challenges, with numerous studies showing that individuals who frequently use heroin during incarceration report engaging in riskier practices than in the community, with one of the factors contributing towards that being limited availability of harm reduction services in prisons. ${ }^{9}$ Heroin use in prison significantly increases the risks of HIV, Hepatitis C (HCV) and Hepatitis B (HBV) infection, ${ }^{10}$ overdose death upon release, ${ }^{11,12}$ criminal activity, ${ }^{13,14}$ and re-incarceration. ${ }^{15}$

The prison population has substantially higher rates of heroin dependence than the general population, ${ }^{16}$ and although many heroindependent prisoners stop using heroin during incarceration, ${ }^{17}$ those who continue using more regularly share drug paraphernalia and are at substantially higher risk of HIV/HCV seroconversion and acts of violence than heroin users in the community. ${ }^{4,18}$

As a total institution, prison has an overwhelming impact on the incarcerated person and their everyday life. Being imprisoned is characterised by deprivation of liberty, restrictions on personal possessions, loss of control, deprivation of security and autonomy, loss of relationships, loneliness and boredom. ${ }^{19-22}$ Prison is an environment with a climate of hostility, suspicion and unpredictability where one faces regular exposure to feelings of isolation and threats of violence. The prison population in England and Wales has doubled in the last twenty years and has now reached its record of $86,388 .{ }^{23}$ This is due to increases in custodial sentencing and sentence lengths. This has resulted in change of composition of the prison population, with rapid increase of prisoners with mental health problems, substance use disorders and histories of self-harm and suicide attempts. ${ }^{1}$ Prisons are no longer holding the most dangerous individuals; instead they have effectively accumulated the most vulnerable ones. ${ }^{22}$

Whilst several in-depth studies have explored the worlds of heroin users in the community, ${ }^{24-26}$ a comprehensive qualitative study of heroin use in prison, examining its social and psychological dimension, has not yet been conducted. Most qualitative studies with incarcerated heroin users have focused on a specific issue, such as drug treatment, ${ }^{27,28}$ injecting drug use, ${ }^{29}$ status and social relations, ${ }^{30}$ drug dealing, ${ }^{19}$ and prison opiate substitute programme. ${ }^{31}$ However, heroin use is a phenomenological experience that has multiple dimensions and needs to be explored beyond its behavioural, social and environmental component. It fundamentally concerns individuals' inner worlds and therefore necessarily exists also on a psychological level.

This study sought to examine participants' lived experience of heroin addiction in prison. It aimed to give voice to heroin users with past experience of incarceration, and to produce insight into the patterns, functions, and social and psychological implications of compulsive heroin use in prison environments. Special emphasis was placed on exploration of meaning participants attach to their heroin use, the purposes it serves, its effects on interpersonal relationships and how it shapes and impacts their daily lives. 


\section{Methodology \\ Design}

This was a qualitative study which used semi-structured one-toone interviews and interpretative phenomenological analysis. IPA was considered the most suitable approach for the topic investigated in this study, as this research aimed to gain understanding of the lived psychological and social experience of heroin addiction in prison and to produce a deep and rich analysis of the phenomenon. Semistructured interviews were used to gather the data as they allowed intimate focus, development of rapport and detailed exploration of individuals' experience, thoughts, feelings and sense-making. ${ }^{32}$ As the phenomenological method does not aim for generalisability of the results, no attempt was made at representativeness or randomisation of the sample. ${ }^{33,34}$ Given the nature of the study's focus, some homogeneity of shared experience was essential.

\section{Participants}

Participants were aged between 35 to 50 years old, were male, and had spent between 10 weeks to 12 years in prison, either on remand or under sentence and had experienced heroin addiction during the time of their incarceration. The exclusion criteria included those who had been court-ordered to a drug rehabilitation programme at the time when the study was conducted. This was in order to avoid participants feeling any sort of pressure for taking part in the study. The four participants were recruited from a local drug service in London. All four participants fitted the DSM-5 criteria of substance use disorder. ${ }^{5}$

\section{Procedure}

Following ethical approval, participants were recruited from a drug service in London. Information sheets were posted in the waiting area, and staff informed service users of the study. Before taking part in the interview, participants signed the consent form which provided information about the nature and purpose of the study. It was further pointed out that taking part is entirely voluntary, that they can choose to withdraw from the study or decline to answer any question at any time without giving a reason to do so and without consequences of any kind. Participants were informed of the confidentiality of the study and that they will be given pseudonyms in the writing of the study, to protect their anonymity. Participants were also informed of the limits of confidentiality in case harm to self or others are disclosed during the interview. They were also given the contact details of the researcher and their supervisor, should they have any complaints, concerns, questions or want a copy or summary of the study results.

Interviews were conducted in counselling rooms at the drug service which were equipped with alarms. The staff at the service was aware of the research being conducted and were available at short notice, should any problems have occurred. The interviews were recorded with participants' permission and lasted between 35 and 45 minutes, with the average time of 38 minutes. Participants were then handed a debrief form with a list of ex-offender organisations and specialised therapeutic services.

\section{Process of analysis}

An interpretative phenomenological analysis was performed and data were analysed as recommended by Smith et al..$^{32}$ The data was reviewed where clusters of themes developed into superordinate themes and the corresponding subthemes. Some originally identified themes were dropped as they did not fit with the superordinate themes. This process was followed for each participant, being mindful of treating each case on its own terms and bracketing the themes and interpretation emerging from the analysis of one case when working on another. Summary tables for each participant had identified the patterns across cases with the aim of integration of findings from analysis of each case. A list of superordinate themes and their subthemes, together with quotes and information about where they appear developed into a table of themes. ${ }^{35}$ This offered a systematic overview and provided the basis for production of the written analysis. During the whole process, the authors consistently referred back to the transcripts, to ensure that the identified themes appropriately represented participants' accounts.

\section{Study findings}

Four superordinate themes emerged from the interpretative phenomenological analysis (IPA) of the four semi-structured interviews. These were as follows: heroin as emotion regulator, relationship with heroin, feelings of isolation and fear, and conceptualisation of heroin on behaviour change.

Throughout the interviews there was a recurring theme of regulation of emotions with heroin. The aim to keep emotions stable and under control was one of the primary motivators for participants' heroin use. Heroin use was presented as an attempt at self-regulation and management of difficult emotional states:

a. So positives, is that it kept my emotions stable. Constantly when I was on gear, I'd feel composed, I don't get angry, I don't get upset, I just deal with stuff, I feel pretty much invincible when I am on it. I don't really feel like I'm in prison, I've always got something to do, it occupied my day. Sort of like having a smoke with my mates in prison, it's similar to having a drink with my mates in the pub when outside. Have a little bit of a laugh about it, then the fun in trying to get it all together, quite an adventure. And I just didn't really think about my problems outside, and stuff like that. (Ben)

b. The ever-present theme in the interviews referred to an attempt to forget reality with the help of heroin. For example, Simon explained that he used heroin" just to pass time really, and numb me from everything, and make me forget about my life and where I am and how I amounted to nothing, that sort of stuff. I don't think it did much else, nothing else good at least, obviously made a lot of things much worse."

Participants referred to the concept of loss that is connected with imprisonment. Incarceration is associated with multiple losses, some of which are irretrievable: loss of liberty, loss of relationships, loss of life opportunities, loss of time and loss of control. ${ }^{19,21}$ The use of heroin becomes a means of coping with these losses.

The associated theme that emerged from the interviews was the practice of self-soothing with heroin. Ben described the difficulty of dealing with feelings of fear and resentment and identifies heroin as a source of relief and as a tool for self-soothing. Another theme that emerged from the interviews is the state of numbness invoked by heroin use. In the following paragraph, Simon refers to feeling of numbness as one of the only real positives of heroin use in prison.

"Well the time just flew by without even realising and well after a while the only real positive was that the time just flew, cos you were always numb. When you've got it you could be on the moon 
and still feel at ease with it, it doesn't matter where you are, police station or prison or whatever, I mean I used everywhere, there was no deterrent, cos my body was craving for it and my mind was telling me that I need it and I'd go to any lengths to get it. All my life was about heroin, it came before my missus and my kids and it had a huge negative impact on my relationships with them so yeah all together lots of downsides and not much to show why it was worth it, apart from keeping me numb". (Simon)

Participants suggested that heroin use brought about the disappearance of problems, worrying thoughts and pain. "I just jumped on board, do you know what I mean. It got me rid of the pain and all". (Mark)

The second subordinate theme that emerged from the interviews was the relationship with heroin. This relationship was often conceptualised as the main relationship that was prioritised over interpersonal relationships.

"It was really the base for everything, waking up every day wanting to do it and looking for it, and I'd be doing it every time I had ability to do it, I wasn't interested in nothing else, not to learn or work or anything. If I was working or doing anything else, I couldn't wait to get back to smoke. So my whole life was really about gear and smoking." (Simon)

Another recurring theme in the interviews was the description of participants' relationship with heroin as an obsession. Participants spoke of constantly thinking and obsessing about heroin, as well as strategising how to obtain it. Simon explained that ". The only time I didn't take it in prison was when I could not get it, but I spent all the time thinking about it then." (Simon)

\section{Similarly, Mark spoke of being obsessed to the extent that heroin made life in prison possible}

"Basically I knew I could not live without it, I mean I thought that back then, obviously I could if I tried but I didn't I guess. And the obsession came and was quite strong at that point, probably this is also an impact of prison environment cos it's so mundane and quite ruthless and heroin helps to get through it, so yeah heroin meant a lot to me during that time."

The obsessive nature of the relationship with heroin was also echoed in Adam's words: "The negative part is definitely also the withdrawal, the physical part I mean but the mental was even worse, I mean my mind was never far from it, it never was. I was always thinking about where to get the drug, heroin or any kind of opiate, I mean it was an obsession. I was obsessed really, no other way to describe it."

The third superordinate theme that emerged from the interviews was the impact of heroin on feelings of isolation and fear. Participants often described relationships as being based on drugs and how users of specific drugs gravitated towards each other. Nevertheless, they also pointed out that these connections were for the sole purpose of obtaining heroin and that as soon as that was accomplished, heroin users resorted to being on their own, distancing themselves from other people.

In the following extract Adam explains that relationships were focused on drugs and emphasises that there were no friendships or meaningful and caring relationships in prison.
"Well if we just go with other inmates first, it was very basic, there was no friendship or relationship there really, it was just focused on getting and using the drugs, that was as far as it went, you were just talking about what's happening and who has the money and who has the gear and who will score and where to use it and stuff like that."

Another theme that emerged in the description of interpersonal relationships was the power dynamics between heroin users and other people, with a particular focus on disproportionate power between heroin users and heroin dealers.

"And then obviously you've gotta deal with people who you're buying it off and they obviously use it as an element of power, you know what I mean, cos they've got something that you want, so they might make you wait for it, they might be chilling with their friends and say come around later, so you've gotta deal with all that. Then the obvious violence that goes with it as well, cos things don't always run smoothly and there's a lot of violence around it. People rob other people, nick their stuff, people don't pay people, so it's kinda like, yeah, looking back I don't know how I had the energy to do it." (Ben)

Relationships in prison were repeatedly described as based on manipulation, exploitation and threat of violence, hence participants regularly resorted to spending time on their own. Isolation is a theme that often emerged in participants' account of their social life in prison.

"Well I kept myself to myself, I didn't have much contact with other prisoners, I'd only speak if I was spoken to, I wanted to avoid any confrontations and conflicts and all that. I'd socialise with anyone really but to a minimum extent, and I don't think my heroin use had much impact on my relationships with them, I mean I didn't actively seek company of other users, but then again I only really hung out with my cellmate who was also a user." (Mark)

Another theme that emerged in the description of interpersonal dynamics in prison was lack of trust.

"There was a lot of disrespect and generally there is a lot of disrespect and lack of trust in jail, between inmates and staff, and between inmates themselves, and obviously drugs make it worse but I think even if there were no drugs it would still be a toxic environment and no one would have any friends, just acquaintances really, cos there are no friendships in prison." (Adam)

In this extract Adam reflects on the climate of disrespect and lack of trust in prison and the impact of heroin use on this dynamic. However, whilst he acknowledges that heroin made the situation worse he also emphasises the impact of prison itself on interactions. He suggests that prison is a toxic, ruthless, dog-eat-dog environment that does not facilitate building friendships or trusting relationships.

The fourth superordinate theme that emerged from the interviews was conceptualisation of heroin on behaviour change. Participants offered very different perspectives on the experience. Adam described it as a horrific life and conceptualised it as terrifying: "Well looking back it was, it was a nightmare really".

In Ben's account, heroin use is presented as a coping mechanism and as a proposed solution to the problem of reality, however he acknowledges that this solution transformed through time and eventually became a problem on its own. Heroin addiction in prison was also conceptualised as a catalyst for change and an 
opportunity for personal growth.

"So it affects it in that way, it might be also in employability terms, but to be honest I find the best way for me is to use my story as a strength, instead of trying to hide from it and escape. And I think this whole experience contributed towards my personal growth, I have quite a lot of ability now that I never used to believe in.” (Ben)

He explains this by referring to the skills he obtained during the experience of heroin addiction as transferrable to many other areas in life. He describes his experience as a valuable lesson and learning opportunity.

"They are kind of transferrable skills in a way, and I used to think of that when I was doing sales as well! Basically everything that's gone wrong in the past, I have learned from it and can be mindful of it in the future. And a lot of that is coming from my life in prison." (Ben)

Similarly, Mark refers to his experience of heroin addiction in prison as playing a key role in the change to his method of drug use. The meaning he made of this change is concerned with the consequent reduction of risk to his health and life.

"It was a phase I had to go through I guess, I mean I started using before I got to prison and I guess I needed that stint in prison to kinda give me a bit of stability and I think I used the experience well and made something positive out of it. I mean I never went back to injecting and I stopped injecting because of being in prison, so yeah this experience was good for me, although I was gutted at the time that I had to be there."

Mark describes prison as a source of stability that allowed him to make positive alterations to his heroin use. Whilst other participants referred to prison primarily as a toxic, mundane and ruthless environment, Mark perceived it as a platform that served as a catalyst for a positive change.

\section{Discussion}

This study aimed to contribute to existing knowledge about psychological and social experiences of heroin addiction in prison which were investigated using an idiographic approach. The main findings of this study included the themes: heroin as emotion regulator, relationship with heroin, feelings of isolation and fear, and conceptualisation on behaviour change. These findings are broadly consistent with previous research. ${ }^{19,29,36}$

To elaborate, the notion of heroin use as a coping mechanism is supported by previous studies, with numerous researchers having proposed conceptualisation of drug use as a coping mechanism which people resort to because they have failed to develop adaptive responses to stress and negative emotional states. ${ }^{37-39}$ Similarly, in accordance with the self-medication hypothesis, ${ }^{36}$ argued that a person who is more sensitive to emotional distress and who has a lower ability to self-regulate is at greater risk for progression from experimental to dependent drug use as a means to cope. Indeed, the results of this study showed that participants used heroin to selfmedicate. Ability to self-soothe in times of distress is essential for healthy emotional functioning and for prevention of emotional over whelmedness. Deficit in the ability to self-soothe is therefore connected with the problem of internalisation of the functions of the caregiver that allow individuals to practice effective self-care, ${ }^{40-42}$ proposed that people who are addicted to heroin have disturbed global ego function of self-regulation. ${ }^{36}$ Milkman \& Frosch, ${ }^{43}$ also suggested that a person's choice of a particular drug is not accidental and that different drugs are chosen to serve individuals in coping with different forms of emotional distress. Further, research has shown that due to opioids' emotional and neuro-chemical relation to attachment, opioid consumption results in affective states that have similar characteristics to the safe haven function. ${ }^{44}$

This study also explored participants' relationship with heroin which emerged as the relationship that was prioritised above individuals' interpersonal relationships and was characterised by obsession and ambivalence. Participants manifested strong attachment to the drug which was experienced as a secure base and safe haven. Participants perceived the drug as an attachment figure, as they gravitated towards it in times of distress and used it as a source of comfort and safety. This is in accordance with previous research on attachment and heroin addiction, ${ }^{38,45-47}$ which argued that due to its neuro-biological properties, heroin users perceive the drug as a substitute attachment figure and use it to compensate for the absence of satisfying relationships.

The findings of this study suggest there is an impact of heroin use on object relations. This manifests itself in the formation of relationships based on drugs, the emergence of disproportionate power dynamics between heroin users and suppliers, the creation of a climate of mistrust, and the tendency of participants to isolate themselves and maintain distance from any meaningful interpersonal contact. Concerns centred on the participants fear of being found out by the authorities for using illicit drugs and how this would impact their parole. ${ }^{4}$ Further, the total institution is governed by a power stratification, one stratum of which is directly related to prison congestion. Whether remand or sentenced, prisoners with drugs problems often oscillate between feelings of empowerment and disempowerment based on their level of addiction and drug accessibility.

The disparity involved in the power dynamics between heroin users and/or dealers became particularly evident during withdrawal. The biopsychosocial discomfort associated with drug withdrawal induced fear and hence isolation. Fear was linked with their concern about being bullied and/or having their drugs removed whether via mandatory or non mandatary means. ${ }^{4}$ Sizable debts can also build up among prisoners creating additional complications. Since a sizable proportion of the prison estate contains prisoners with mental health problems, ${ }^{48,49}$ this becomes compounded. Certainly the participants in this study reported mistrust with both the authorities and other prisoners where heroin was both a 'blessing and a curse' and held a dual purpose. For example, previous studies, ${ }^{36,44}$ have shown that heroin is not chosen at random but to serve specific emotional and social needs, so one possibility is that people who experience problems in forming close and trusting relationships gravitate towards heroin use, and then later their heroin use additionally complicates their interpersonal relations and limits their potential for forming trusting relationships. In some instances participants reported their reluctance in discussing their drug problems with prison staff owing to the potential consequences and repercussions of doing so. This could result in being sanctioned by the authorities and/or being deemed 'a grass' by prisoners, resulting in violence and bullying. Unlike drug users in the community, it becomes an impossibility to escape bullying in prison. Further research would be beneficial to explore this more in detail. 
Participants' ambivalence was matched with their desire to make changes to their substance use problem. The transtheoretical model of behaviour change looks at intentional behaviour change via a biopsychosocial perspective. The stages include pre-contemplation, contemplation, preparation, action, maintenance and relapse. ${ }^{50}$ Certainly this behaviour change was reflected in the superordinate theme, 'Conceptualisation of heroin on behaviour change'. This reflected the preparation and action transitions of the participants mind set about their heroin use. However, this oscillated to denial or pre-contemplation, ambivalence and relapse when the reality of prison existence, fear, bullying and vulnerability became reinforced in everyday prison life. Future research may wish to establish how the application of this model in prison compares to that in the community.

The present study has several limitations. As it only included four participants, it cannot be understood as representative of all people with experience of heroin addiction in prison. Further research would benefit from including more participants via a socioeconomic and cultural cohort. However, it is worth noting that this analysis brought topics and themes that seem consistent with findings of other studies. ${ }^{19,29,36}$ Additionally, this study is qualitative and idiographic, and as such does not aim to produce generalisability but to capture detailed experience of a small number of participants.

This study aimed to contribute to the existing knowledge about psychological and social experience of heroin addiction in prison and investigated this issue using an idiographic approach. It is hoped that our findings, although they cannot be generalised to the wider prison population, nevertheless make an important contribution towards understanding of the phenomenon. As such, they can form the basis for practical interventions to effectively support incarcerated individuals who are addicted to heroin. Drugs misuse negatively impacts both rehabilitation and reoffending patterns in prison and in the community. ${ }^{1}$ In addition to the current drug services available, it is hoped that the prison service will employ less punitive strategies in the detection and punishment of illicit drug users and further, that custodial sentencing will incarcerate violent offenders rather than those who are vulnerable with complex needs and are deemed 'petty' criminals.

\section{Compliance with ethical standards}

All procedures followed were in accordance with the ethical standards of the responsible committee on human experimentation (institutional and national) and with the Helsinki Declaration of 1975, as revised in 2000 (5). Informed consent was obtained from all service users and all ethical guidelines were in accordance with the British Psychological Society (BPS, 2009) code of ethics and conduct.

\section{Acknowledgements}

None.

\section{Conflict of interest}

Lana Durjava, Amanda Visick and Samantha Banbury, declare no conflict of interest.

\section{References}

1. HM Inspectorate of Prisons. Changing patterns of substance misuse in adult prisons and service response. A thematic review. 2015. $85 \mathrm{p}$
2. Boys A, Farrell M, Bebbington P, et al. Drug use and initiation in prison: results from a national prison survey in England and Wales. Addiction. 2002;97(12):1551-1560.

3. Strang J, Gossop M, Heuston J, et al. Persistence of drug use during imprisonment: relationship of drug type, recency of use and severity of dependence to use of heroin, cocaine and amphetamine in prison. Addiction. 2006;101(8):1125-1132.

4. Banbury S, Lusher J, Morgan W. Male Sexual Aggressors in the British Prison Service: An Exploratory Study. International Journal of Mental Health and Addiction. 2016;14(4):370-384.

5. American Psychiatric Association. Diagnostic and statistical manual of mental disorders. 5th ed. VA, USA: American Psychiatric Publishing; 2013.

6. Gordon MS, Kinlock TW, Schwartz RP, et al. A randomized clinical trial of methadone maintenance for prisoners: findings at 6 months post-release. Addiction. 2008;103(8):1333-1342.

7. Keller TE, Catalano RF, Haggerty KP, et al. Parent figure transitions and delinquency and drug use among early adolescent children of substance abusers. Am J Drug Alcohol Abuse. 2002;28(3):399-427.

8. Mark TL, Woody GE, Juday T, et al. The economic costs of heroin addiction in the United States. Drug Alcohol Depend. 2001;61(2):195-206.

9. Hedrich D, Alves P, Farrell M, et al. The effectiveness of opioid maintenance treatment in prison settings: a systematic review. Addiction. 2012;107(3):501-517.

10. Jürgens R, Ball A, Verster A. Interventions to reduce HIV transmission related to injecting drug use in prison. The Lancet infectious diseases. 2009;9(1):57-66.

11. Degenhardt L, Bucello C, Mathers B, et al. Mortality among regular or dependent users of heroin and other opioids: a systematic review and meta-analysis of cohort studies. Addiction. 2011;106(1):32-51.

12. Farrell M, Marsden J. Acute risk of drug-related death among newly released prisoners in England and Wales. Addiction. 2008;103(2):251-255.

13. Kinlock TW, O'Grady KE, Hanlon TE. Prediction of the criminal activity of incarcerated drug-abusing offenders. Journal of Drug Issues. 2003;33(4):897-920.

14. Kinlock TW, Gordon MS, Schwartz RP, et al. A Study of Methadone Maintenance for Male Prisoners 3-Month Postrelease Outcomes. Crim Justice Behav. 2008;35(1):34-47.

15. Hanlon TE, Nurco DN, Bateman RW, et al. The response of drug abuser parolees to a combination of treatment and intensive supervision. The Prison Journal. 1998;78(1):31-44.

16. Fazel S, Bains P, Doll H. Substance abuse and dependence in prisoners: a systematic review. Addiction. 2006;101(2):181-191.

17. Darke S, Kaye S, Finlay-Jones R. Drug use and injection risktaking among prison methadone maintenance patients. Addiction. 1998;93(8):1169-1175.

18. Zamani S, Farnia M, Torknejad A, et al. Patterns of drug use and HIV-related risk behaviors among incarcerated people in a prison 
in Iran. J Urban Health. 2010;87(4):603-616.

19. Crewe B. Prison drug dealing and the ethnographic lens. Howard Journal of Criminal Justice. 2006;45(4):347-368.

20. Crewe B. The prisoner society: Power, adaptation and social life in an English prison. Oxford University Press, USA; 2009. 532 p.

21. Goffman E. Asylums: Essays on the social situation of mental patients and other inmates. London, UK; Penguin Random House; $1961.400 \mathrm{p}$.

22. Liebling UA. Prisons in transition. Int $J$ Law Psychiatry. 2006;29(5):422-430.

23. Ministry of Justice. Annual report and accounts. 2015-2016. 140 p.

24. Bourgois P. The moral economies of homeless heroin addicts: confronting ethnography, HIV risk, and everyday violence in San Francisco shooting encampments. Subst Use Misuse. 1998;33(11):2323-2351.

25. Grund JPC. Drug use as a social ritual: Functionality, symbolism and determinants of self-regulation. Rotterdam: Instituut voor Verslavingsonderzoek (IVO). 1993.

26. Wakeman S. Moral Economy of Heroin in 'Austerity Britain'. Critical Criminology. 2016;24(3):363-377.

27. Duggan JM. Ex-prisoners'perspectives on prison drug treatment in Ireland. Dublin: Dublin Institute of Technology. 2015.

28. Frank VA, Dahl HV, Holm KE, et al. Inmates' perspectives on prison drug treatment: A qualitative study from three prisons in Denmark. Probation Journal. 2015;62(2):156-171.

29. Tompkins CNE. Neale J, Sheard L, et al. Experiences of prison among injecting drug users in England: A qualitative study. International Journal of Prisoner Health. 2007;3(3):189-203.

30. Crewe B. Prisoner society in the era of hard drugs. Punishment \& Society. 2005;7(4):457-481.

31. Mjåland K. The paradox of control: An ethnographic analysis of opiate maintenance treatment in a Norwegian prison. Int J Drug Policy. 2015;26(8):781-789.

32. Smith JA, Flowers P, Larkin M. Interpretative phenomenological analysis: Theory, method and research. London: Sage. Qualitative Research in Psychology. 2009;6(4):346-347.

33. Schofield JW. Increasing the generalizability of qualitative research. The qualitative researcher's companion. 2002. p. 171-203.

34. Smith BA. The problem drinker's lived experience of suffering: an exploration using hermeneutic phenomenology. $J$ Adv Nurs. 1998;27(1):213-222.
35. Willig C. Introducing qualitative research in psychology. Maidenhead: Open University Press. 2013.

36. Khantzian EJ. The self-medication hypothesis of substance use disorders: a reconsideration and recent applications. Harv Rev Psychiatry. 1997;4(5):231-244.

37. Khantzian EJ, Mack JE, Schatzberg AF. Heroin use as an attempt to cope: clinical observations. Am J Psychiatry. 1974;131(2):160-164.

38. Petraitis J, Flay BR, Miller TQ, et al. Illicit substance use among adolescents: a matrix of prospective predictors. Subst Use Misuse. 1998;33(13):2561-2604.

39. Mate G. In the Realm of Hungry Ghosts: Close Encounters with Addiction. Berkeley: USA; North Atlantic Books. 2009.

40. Žvelc G. Addiction as an attempt at self-regulation - Contemporary psychoanalytic theories of addiction. Horizons of Psychology. 2001;10(3):57-74.

41. Khantzian EJ. The ego, the self, and opiate addiction: Theoretical and treatment considerations. In: Blaine JD, Julius DA, editors. Psychodynamics of drug dependence. Northvale, NJ: Jason Aronson; 1993. p. 101-117.

42. Wurmser L. Psychoanalytic considerations of the etiology of compulsive drug use. J Am Psychoanal Assoc. 1974;22(4):820-843.

43. Milkman H, Frosch WA. On the preferential abuse of heroin and amphetamine. J Nerv Ment Dis. 1973;156(4):242-248.

44. Schindler A, Thomasius R, Petersen K, et al. Heroin as an attachment substitute? Differences in attachment representations between opioid, ecstasy and cannabis abusers. Attach Hum Dev. 2009;11(3):307-330.

45. Insel TR. Is social attachment an addictive disorder? Physiol Behav. 2003;79(3):351-357.

46. Reiner A. The triune brain in evolution: Role in paleocerebral functions. In: Paul D MacLean, editor. New York: Plenum. Science. 1990;250(4978):303-305.

47. Mortazavi Z, Sohrabi F, Hatami HR. Comparison of attachment styles and emotional maturity between opiate addicts and nonaddicts. Annals of Biological Research. 2012;3(1):409-414.

48. Ministry of Justice. Statistics of mentally disordered offenders, England and Wales. Ministry of Justice statistics bulletin. 2008.

49. Ministry of Justice. Annual tables: offender management caseload statistics. Ministry of Justice statistics bulletin. 2012.

50. Prochaska J, DiClemente C. Stages and processes of self change and smoking. Toward an integrated model of change. $J$ Consult Clin Psychol. 1983;51(3):390-395. 